\title{
Chlamydia trachomatis-specific antibodies in patients with pelvic inflammatory disease: comparison with isolation in tissue culture or detection with polymerase chain reaction
}

J J H Theunissen, W Minderhoud-Bassie, J H T Wagenvoort, E Stolz, M F Michel, F J M Huikeshoven

\begin{abstract}
Objective-The detection of acute phase antibodies against $C$ trachomatis and its comparison with tissue culture or polymerase chain reaction (PCR) on samples of cervix and urethra obtained from patients with pelvic inflammatory disease (PID).

Methods-In the academic hospital Dijkzigt, Rotterdam, The Netherlands, prospective investigations were performed on 49 consecutive patients who were admitted with the diagnosis of PID. Infections with $C$ trachomatis were traced using tissue culture, PCR or by determining acute phase IgG and IgM antibodies. Differences between the sensitivities of serology and tissue culture or PCR were calculated using the Fisher exact test.

Results-C trachomatis infection was detected more often in PID patients using serology in comparison with PCR ( $p<$ $0.05)$ or tissue culture $(p<0.05)$. All patients who were positive for $C$ trachomatis in the PCR and three of the four patients who were positive in tissue culture also had acute phase antibodies.

Conclusion-The establishing of acute C trachomatis infections in PID patients on the basis of serology was superior to either tissue culture or PCR on samples obtained from cervix and urethra.
\end{abstract}

(Genitourin Med 1994;70:304-307)

Department of Dermato-Venereology

J J H Theunissen

E Stolz

Department of Obstetrics and Gynaecology W Minderhoud-Bassie F J M Huikeshoven

Department of Clinical Microbiology J H T Wagenvoort M F Michel

Erasmus University, Rotterdam,

The Netherlands

Address correspondence to: J J H Theunissen National Institute of Public Health and Environmental Protection, Laboratory of Water and Food Microbiology, PO Box 1, 3720 BA Bilthoven,
The Netherlands.

Accepted for publication 18 May 1994

\section{Introduction}

The role of Chlamydia trachomatis as the cause of pelvic inflammatory disease (PID) is well known. ${ }^{12}$ In a Norwegian study, it was observed that more than $50 \%$ of the PID cases were caused by chlamydia, whereas Neisseria gonorrhoeae played a more subordinate role. ${ }^{3}$ A complicated $C$ trachomatis infection often begins as a clinically benign condition which in most cases remains undiagnosed. This can, in a later stage of infection, lead to tubal damage and subsequently to infertility. In some cases, $C$ trachomatis can be cultured from the fallopian tubes, ${ }^{4}$ from the endometrium ${ }^{5}$ or the peritoneal fluid. ${ }^{6}$ In a recent Swedish study, $C$ trachomatis in samples from tubes and endometrium in a group of infertile women were detected more efficiently using direct immunofluorescence (DFA) than in tissue culture.
In the Dutch setting, obtaining samples from tubes and endometrium is often regarded as imposing an unnecessary burden on the patient. Moreover, because culturing of $C$ trachomatis from the samples from tubes and cervix in an acute PID appears to be less sensitive, ${ }^{7}$ an attempt would be made to establish the infection on the basis of serology. In this study, enzyme-linked fluorescent assay (ELFA) was used to detect IgM and IgG antibodies instead of the more laborious microimmunofluorescent (MIF) technique. ${ }^{8}$

\section{Materials and methods \\ Patients}

Forty-nine women who had been admitted consecutively at the Department of Obstetrics and Gynaecology of the Academic Hospital Rotterdam-Dijkzigt and who satisfied the clinical criteria for acute PID were enrolled in this study. The clinical diagnosis of PID was based on the presence of at least the first four and one or more of the following criteria ${ }^{5-9}$ :

1. History of lower abdominal pain. 2 . Presence of lower abdominal tenderness. 3. Cervical motion tenderness. 4. Adnexal tenderness. 5. Body temperature $>38^{\circ} \mathrm{C}$. 6 . Leucocytosis $>10500 / \mathrm{mm}^{3}$. 7. Erythrocyte sedimentation rate $(E S R)>20 \mathrm{~mm} /$ first hour. 8. Abnormal vaginal discharge. 9. Abnormal vaginal bleeding. If, on the basis of the clinical criteria, the diagnosis PID was made, samples for culture and serology were obtained and antibiotic treatment was initiated. After several days of antibiotic treatment the clinical course in 17 patients made the original PID diagnosis, based on clinical criteria only, doubtful. In these cases laparoscopy was performed. In 15 of these 17 patients laparoscopy showed signs of PID and in two patients there was no pathology at all and an early resolution of PID was assumed.

Cervical and urethral samples for $C$ trachomatis cultures and for PCR on chlamydiaspecific DNA were obtained using a swab with a metal holder (Medical Wire \& Equipment Co. Ltd., Wiltshire, UK). Swabs from both sample sites were transported in one tube of 2SP medium containing $0.2 \mathrm{M}$ sucrose (Merck, Darmstadt, Germany), 49 mM glutamine (Sigma Chem. Co. St. Louis, MO), $10 \%$ foetal calf serum (FCS) (Hyclone Lab. Inc. Logan, Utah), $18 \mu \mathrm{g} / \mathrm{ml}$ gentamicin, $23 \mu \mathrm{g} / \mathrm{ml}$ vancomycin and $2.5 \mu \mathrm{g} / \mathrm{ml}$ amphotericin $\mathrm{B}$ in $20 \mathrm{mM}$ phosphate buffer and 
stored at $4^{\circ} \mathrm{C}$ if cultured within $24 \mathrm{~h}$ or frozen at $-70^{\circ} \mathrm{C}$, if it was not possible to culture within that period. In each patient at least two sera were collected at about 10 days interval for the estimation of IgG and IgM antibodies against $C$ trachomatis. Prior to sampling for $C$ trachomatis and chlamydia-specific DNA, samples were collected from cervix, urethra and rectum for culture of $N$ gonorrhoeae.

\section{C trachomatis culture}

$C$ trachomatis was isolated from samples obtained from the patients according to the method described by Thewessen et al. ${ }^{9}$ In this paper no statistical difference between sensitivities of HeLa 229 or McCoy cells, when isolating $C$ trachomatis in clinical samples, could be observed. A microtitre plate with a monolayer of HeLa 229 cells was preincubated with $15 \mu \mathrm{g} / \mathrm{ml}$ DEAE in Hank's Balanced Salt Solution (Flow Labs., Irvine, Scotland). After mixing, $0.2 \mathrm{ml} /$ well of each cervix/urethra sample from the patient was set up in duplicate. The plates were then centrifuged at $3000 \mathrm{~g}$ for $1 \mathrm{~h}$ and subsequently cultured for $48 \mathrm{~h}$ in Eagle's modification of minimal essential medium (Flow) containing $10 \%$ FCS, $2 \mathrm{mM}$ glutamine, $1 \%$ vitamins, $0.42 M$ glucose, $0.5 \mu \mathrm{g} / \mathrm{ml}$ cycloheximide (Sigma), $18 \mu \mathrm{g} / \mathrm{ml}$ gentamicin, $23 \mu \mathrm{g} / \mathrm{ml}$ vancomycin and $2.5 \mu \mathrm{g} / \mathrm{ml}$ amphotericin B. The plates were then fixed and stained with anti$C$ trachomatis monoclonal antibodies (Microtrak, Syva Co., Palo Alto, Calf.) and examined for inclusions.

C trachomatis-specific polymerase chain reaction (PCR)

The PCR on $C$ trachomatis-specific DNA was performed according to the method described by Claas et al. ${ }^{10}$ DNA was extracted from 0.5 $\mathrm{ml}$ cervix/urethra sample from each patient. Two sets of oligonucleotide primers were used. The first set (R1 = GTGGATAGTCTCAACCCTAT, R2 = TATCTGTCCTTGCGGAAAAC), was derived from $16 \mathrm{~S}$ rRNA gene sequences of $C$ psittaci ${ }^{11}$ and generated 208-bp amplified products with all three chlamydia species. The second set $(\mathrm{T} 1=$ GGACAAATCGTATC TCGG, T2 = GAAACCAACTCTACGCTG was derived from sequences of the common endogenous plasmid of $C$ trachomatis ${ }^{12}$ and generated 517bp amplified products with all known $C$ trachomatis serovars. After 40 cycles, the amplification product was analysed on a $2 \%$ agarose gel.

\section{Enzyme-linked fluorescent assay (ELFA)}

The ELFA was performed as described previously. ${ }^{13}$ Wells of PVC microtitre plates were coated with $50 \mu \mathrm{l}$ of a $10 \mu \mathrm{g} / \mathrm{ml}$ elementary bodies (EB) suspension of the $C$ trachomatis serotypes $\mathrm{E}$ (strain UW-5/cx), F (strain ICCal3), H (strain UW-4/Cx), I (strain UW12/Ur), J (strain UW-36/Cx) and LGV2 (strain 343/Bu) in $0.1 \mathrm{M}$ carbonate/bicarbonate buffer ( $\mathrm{pH} 9 \cdot 6)$. After an overnight incubation at $4^{\circ} \mathrm{C}$, the unoccupied binding-sites were blocked with PBS containing $2 \%$ BSA.
The plates were subsequently rinsed with PBS containing $1 \%$ BSA and $0.05 \%$ Tween-20 (PBST) and incubated with $50 \mu$ ldiluted test serum (1:250 for determining $\operatorname{IgM}$ and $1: 1000$ for determining $\operatorname{IgG}$ ) at $22^{\circ} \mathrm{C}$ for 45 min. The plates were then rinsed with PBST and incubated at $22^{\circ} \mathrm{C}$ for $45 \mathrm{~min}$ with either $50 \mu \mathrm{l}$ of 1:8000 dilution of anti-human IgG biotin (Boehringer, Mannheim, Germany) or with $50 \mu \mathrm{l}$ of 1:250 dilution of anti-human IgM which had been coupled to $\beta$-galactosidase. The plates were then rinsed with PBST and those for IgG titre determination incubated for a further $45 \mathrm{~min}$ at $22^{\circ} \mathrm{C}$ after addition of $50 \mu \mathrm{l}$ of 1:4000 dilution of streptavidin $\beta$-galactosidase (Boehringer) and subsequently rinsed with PBST. The final step comprised a $1 \mathrm{~h}$ incubation at $37^{\circ} \mathrm{C}$ after addition of $100 \mu \mathrm{l}$ of $0.25 \mathrm{mg} / \mathrm{ml} \mathrm{4-methy-}$ lumbelliferyl $\beta$-D-galactoside (Sigma) in a buffer containing $44 \mathrm{mM} \mathrm{K} \mathrm{HPO}_{4}, 55 \mathrm{mM}$ $\mathrm{KH}_{2} \mathrm{PO}_{4}, 4 \mathrm{mM} \mathrm{MgCl}$ (pH 7.6). The reaction was stopped by adding $100 \mu \mathrm{l}$ of $1 \mathrm{M}$ $\mathrm{Na}_{2} \mathrm{CO}_{3}$. Fluorescence was measured at 480 nm using FLUOROSKAN 1 (Flow). The criteria for an acute infection were: an IgM titre $\geq 1: 500$ (corresponding with a MIF titre $\geq 1: 32$ ), and/or an IgG titre $\geq 1: 16000$ (MIF titre $\geq 1: 512$ ), and/or a four-fold increase/decrease in IgM and/or a four-fold increase in IgG titre. The cut-off points of an acute infection as determined by MIF were described by Grayston et al. ${ }^{14}$ The sensitivity of the ELFA technique is similar to that of the MIF. ${ }^{13}$ No evidence for cross-reactions between antibodies directed against $C$ trachomatis and antibodies directed against $C$ pneumoniae could be observed using ELFA. ${ }^{13}$

\section{Statistical analysis}

Statistical differences between the sensitivity of tissue culture and PCR for $C$ trachomatis on the one hand and $C$ trachomatis serology on the other hand were calculated using the Fisher exact test.

\section{Results}

Six out of the 49 patients were positive in PCR on $C$ trachomatis- specific DNA. Four patients were positive in culture. Of these four culture positive patients, three were also positive in PCR. In all six patients in whom $C$ trachomatis- specific DNA was demonstrated using PCR and in three out of the four patients in whom $C$ trachomatis cultures were positive, acute phase antibodies were also observed. One patient was positive in culture only.

The prevalence of acute phase IgM and/or IgG antibodies against $C$ trachomatis is shown in the table. Combining high IgG/IgM titres with an increase or decrease in IgM titres and an increase in IgG titres showed an acute antibody titre in 16 out of $49(32 \cdot 7 \%)$ patients. This implies that a total of nine patients were positive in serology only. There was a statistically significant difference between the sensitivity of $C$ trachomatis culture as compared with $C$ trachomatis serology $(p<0.05)$ and 
Distribution of acute phase antibodies against $C$ trachomatis in patients with pelvic inflammatory disease

\begin{tabular}{ll}
\hline Antibody group & Number of patients (\%) \\
\hline 1. IgM $\geq 1 / 500$ & $6 / 49(12 \cdot 2)$ \\
2. IgG $\geq 1 / 16000$ & $5 / 49(10 \cdot 2)$ \\
3. four-fold increase/decrease & $4 / 49(8 \cdot 2)$ \\
in IgM titre & \\
4. four-fold increase in IgG titre & $9 / 49(18 \cdot 4)$ \\
5.1 and 2 combined & $9 / 49(18 \cdot 4)$ \\
6.3 and 4 combined & $11 / 49(22 \cdot 4)$ \\
7. $1,2,3$ and 4 combined & $16 / 49(32 \cdot 7)$ \\
8. Negative & $33 / 49(67 \cdot 3)$ \\
\hline
\end{tabular}

between the sensitivity of PCR as compared with serology $(p<0.05)$. In two out of six PCR-positive patients, an IgG titre $\geq 1: 16000$ was observed, in two patients a four-fold increase in the IgG titres were observed and in two patients, both a four-fold increase in the titres of $\operatorname{IgM}$ and $\operatorname{IgG}$ as well as an IgM titre of 1:1000 and an IgG titre of 1:16000 were observed.

$N$ gonorrhoeae was cultured from the samples of cervix and/or urethra and/or rectum in 13 out of the $49(26.5 \%)$ patients. In three out of the $49(6 \cdot 1 \%)$ patients there were, in culture and serology, indications of both chlamydial and gonococcal infections. Three chlamydia culture negative and PCR negative patients were found to be positive in both $N$ gonorrhoeae culture as in $C$ trachomatis serology. So a total of six patients showed signs of both chlamydial and gonococcal infection.

\section{Discussion}

In the literature the best methods to trace the cause of PID appears to be tissue culture or direct immunofluorescence on the samples from tubes or endometrium..$^{715}$ In the Netherlands, obtaining samples from the tubes for detection of $C$ trachomatis is generally considered as imposing an unnecessary burden on the patient. Moreover, Thejls et al reported that the sensitivity of primary culture for $C$ trachomatis established from the samples from tubes or endometrium was limited compared with the sensitivity with which chlamydia antigens were demonstrated using direct immunofluorescence. However, in another study, it was reported that the samples from tubes and endometrium had to be passaged several times in culture before $C$ trachomatis could be detected. ${ }^{15}$

In our study, $C$ trachomatis was cultured from the cervix in $8.2 \%$ of the patients with PID, whereas in other studies $C$ trachomatis was isolated from the cervix in $36-49 \%$ of patients with the same diagnosis. ${ }^{16}$ As the sensitivity of the $C$ trachomatis-specific PCR for culture confirmed urogenital specimens was shown to be excellent, ${ }^{10}$ the demonstration of $C$ trachomatis- specific DNA in the PCR might have increased the sensitivity of tissue culture of samples from the cervix. Therefore, together with chlamydia culture we performed PCR on all samples. Chlamydia-specific DNA was demonstrated in six $(12.2 \%)$ of the patients. Combination of tissue culture and PCR demonstrated infection with $C$ trachomatis in the cervix as a possi- ble cause of PID in seven (14.3\%) patients but was lower than that reported previously. ${ }^{1515}$ However, in our opinion, this percentage $(14 \cdot 3 \%)$ was the maximum that could be achieved using this form of detection in the patients in this study.

In order to improve the sensitivity for detection of acute $C$ trachomatis infection in PID patients without using invasive techniques, acute IgG/IgM titres against a representative set of chlamydial antigens were determined. From the figures in the table it can be seen that a combination of high IgM/IgG titres and four-fold increase/ decrease of IgM titre and a four-fold increase in IgG titre had the highest sensitivity for detecting acute phase antibodies against $C$ trachomatis $(32 \cdot 7 \%$ of the patients). Determining the conversions in IgG titres (18.4\%) made the largest contribution. This was followed by high IgM titre $(12 \cdot 2 \%)$. Determining high IgG titre $(10 \cdot 2 \%)$ and conversion in IgM titre $(8.2 \%)$ made minor contributions. In two patients with an acute antibody titre, only high IgG titres were observed. It was previously reported that IgG antibodies can remain in the circulation for a long period after $C$ trachomatis-caused PID. ${ }^{17}$ Although these two patients had satisfied the clinical criteria for an acute PID, it could not be totally excluded that both these patients had chronic $C$ trachomatis infection. Serum conversions, often observed in our group of PID patients, were hardly observed in patients with uncomplicated urogenital $C$ trachomatis infections. ${ }^{13}$ To our knowledge, serum conversions were not determined in the previous investigations on PID patients. However, it was observed, that the average titre of IgM/IgG antibodies in a group of PIDpatients in whom $C$ trachomatis cultures were positive was higher than that in a group of PID-patients from whom no $C$ trachomatis could be cultured. ${ }^{17}$ This was in accordance with our results, as we observed acute phase titres in all but one culture positive patients and in all PCR positive patients.

In $26.5 \%$ of the patients, $N$ gonorrhoeae was isolated from the cervix. In our study, the incidence of gonorrhoea was similar to that observed by others. ${ }^{145}$ Altogether in 24 (49\%) out of 49 PID patients an infection caused by $C$ trachomatis and/or $N$ gonorrhoeae could be detected.

The best method to establish the diagnosis for the suspected causes of PID was DFA on samples from tubes and endometrium. ${ }^{7}$ In the present study, the number of infections demonstrated using serology was comparable to that demonstrated by Thejls et al using DFA. ${ }^{7}$ In our hands, the role of $C$ trachomatis as a possible cause of PID was demonstrated with a higher sensitivity using serology than either culturing of or PCR on samples from the cervix. As compared with DFA on the samples from tubes or endometrium, serology also hardly imposes any unnecessary burden on the patient.

We thank Dr B Tank for correcting the English text. 
1 Mårdh P-A, Ripa T, Svensson L, Weström L. Role of Chlamydia trachomatis infection in acute salpingitis. N Engl Y Med 1977;269:1377-9.

2 Bruh RC, Peeling R, Maclean I, McDowell J, Persson K, Osser S. Postabortal Chlamydia trachomatis salpingitis: correlating risk with antigen-specific serological responses and with neutralization. $\mathcal{F}$ Infect Dis 1987; 155:749-55.

3 Gjønnaess H, Dalaker K, Ánestad G, Mårdh P-A, Kvile G, Bergan T. Pelvic inflammatory disease: etiologic studies with emphasis on chlamydial infection. Obstet Gynecol 1982;59:550-5.

4 Stacey C, Munday P, Thomas B, Gilchrist C, TaylorRobinson D, Beard R. Chlamydia trachomatis in the fallopian tubes of women without laparoscopic evidence of salpingitis. Lancet 1990;336:960-3.

5 Sweet RL, Schachter J, Robbie MO. Failure of antibiotics to eradicate Chlamydia trachomatis in the endometrium eradicate Chlamydia trachomatis in the endometrium 1983;250:2641-5.

6 Henry-Suchet J, Catalan F, Loffredo V, et al. Chlamydia trachomatis associated with chronic inflammation in abdominal specimens from women selected for tuboplasty. Fertil Steril 1981;36:599-605.

7 Thejls H, Gnarpe J, Lundkvist Ö, Heimer G, Larsson G, Victor A. Diagnosis and prevalence of persistent chlamydia infection in infertile women: tissue culture, direct antigen detection, and serology. Fertil Steril 1991;55: 304-10.

8 Wang SP, Grayston JT. Microimmunofluorescence antibody responses in Chlamydia trachomatis infections. In: body responses in Clamy Mårdh PA, Holmes KK, Oriel JD, Piot P, Schachter J eds. Chlamydial Infections. Amst

9 Thewessen EAPM, Freundt I, Van Rijsoort-Vos JH, Stolz E, Michel MF, Wagenvoort JHT. Comparison of HeLa
229 and McCoy cell cultures for the detection of Chlamydia trachomatis in clinical specimens. $f$ Clin Microbiol 1989;27:1399-1400.

10 Claas HJC, Wagenvoort JHT, Niesters HGM, Tio TT, Van Rijsoort-Vos JH, Quint WGV. Diagnostic value of the polymerase chain reaction for chlamydia as determined in a follow-up study. F Clin Microbiol 1991 29:42-5.

11 Wiesburg WG, Hatch TP, Woese CR. Eubacterial origin of chlamydiae. $\mathcal{F}$ Bacteriol 1986;167:570-4.

12 Sriprakash KS, Macavoy ES. Characterisation and sequence of a plasmid from the trachoma biovar of Chlamydia trachomatis. Plasmid 1987;18:205-14.

13 Theunissen JJH, Van Heijst BYM, Chin-A-Lien RAM, Wagenvoort JHT, Stolz E, Michel MF. Detection of antibodies in patients with uncomplicated Chlamydia trachomatis infection: a comparison between enzyme linked fluorescent assay and isolation in cell culture. Int $\mathcal{F}$ STD AIDS 1993;4:43-8.

14 Grayston JT, Wang SP, Foy HM, Kuo CC. Seroepidemiology of Chlamydia trachomatis infection. In Mårdh PA, Holmes KK, Oriel JD, Piot P, Schachte $\mathrm{J}$, eds. Chlamydial Infections. Amsterdam: Elsevie Biomedical Press, 1982 Vol. 2:405-19.

15 Shepard MK, Jones RB. Recovery of Chlamydia trachomatis from endometrial and fallopian tube biopsies in women with infertility of tubal origin. Fertil Steril 1989;52 232-8.

16 Miettinen A, Heinonen PK, Teisala K, Punnonen R, Paavonen J. Antigen specific serum antibody response to Chlamydia trachomatis in patients with acute pelvic inflammatory disease. $\mathcal{F}$ Clin Pathol 1990;43:758-61.

17 Puolakkainen M, Vesterinen E, Purola E, Saikku P Paavonen J. Persistence of chlamydial antibodies after pelvic inflammatory disease. $\mathcal{F}$ Clin Microbiol 1986;23: pelvic inf 